\title{
¿Es segura la técnica combinada espinal-epidural en analgesia para trabajo de parto en instituto de formación?
}

\author{
Roland H. ${ }^{1}$, Priotto A. ${ }^{1}$ \\ 1 Hospital Privado, Córdoba, Argentina.
}

Introducción: El dolor del parto es de los dolores más intensos que una mujer puede experimentar. Los bloqueos neuroaxiales son los medios más efectivos para proporcionar analgesia durante la dilatación y el parto,por ser más flexibles y con menos efectos depresores sobre la madre y el feto.

La técnica combinada espinal-epidural (TCEE) ofrece analgesia de comienzo rápido, con riesgo mínimo de toxicidad o de bloqueo motor intenso, permite prolongar la analgesia tanto como sea necesario y se puede realizar anestesia para cesárea.

La realización de técnicas neuroaxiales dependen de la pericia y experiencia del operador y en instituciones formadoras la incidencia de complicaciones podría aumentar.

El alivio del dolor inmediato, luego de la punción raquídea, permite realizar la punción epidural y colocación de catéter con mayor tiempo y cuidado, para evitar complicaciones.

Hipótesis: La TCEE en trabajo de parto, es segura, efectiva y con baja tasa de reacciones adversas.

Objetivos:

-Valorar eficacia de TCEE en mismo espacio lumbar, técnica de Dogliotti, avance intermitente.

-Evaluar incidencia de complicaicones y seguridad de la técnica en institución formadora.

Material y Métodos: Estudio longitudinal, retrospectivo, de 2.171 pacientes, consecutivas, embarazadas a término, con parto vaginal electivo y que solicitan analgesia para el trabajo de parto, entre 01/05/2010 y 30/04/2015 en Hospital Privado de Córdoba.

Cada paciente firmo consentimiento. Bajo Asepsia, se realiza TCEE, primero punción raquídea, al retirar aguja espinal se marca distancia desde la piel hasta la punta de la aguja, luego se la enfrenta a la aguja epidural y se mide la distancia que tendremos desde la piel hasta la membrana Duramadre, así determinamos hasta donde podremos avanzar de manera "segura" y cuando estamos ante el riesgo de una PDA. (Figuras 1,2) Luego se realiza epidural, en el mismo espacio lumbar, técnica pérdida de la resistencia, avance intermitente.

Resultados: Muestra final: 2.171 pacientes, edades: 13-44 años, peso promedio 72,16 kg, altura promedio 1,63 mts. El $29,8 \%$ de procedimientos fueron realizados por anestesiólogos staff y $70,2 \%$ por residentes supervisados.

Registramos complicaciones en 3,15\% de los procedimientos realizados (69 casos), 54 correspondieron a complicaciones menores y de resolución inmediata, 15 pacientes presentaron complicaciones que requirieron intervenciones posteriores (Tabla).

Conclusiones: La TCEE es una técnica segura para la analgesia del trabajo de parto, ya que proporciona alivio inmediato del dolor, presenta pocas reacciones adversas y permite ser realizada por anestesiólogos en formación sin inconvenientes.

https://doi.org/10.25237/congresoclasa2019.91 